\title{
The Oslo Health Study: Reminding the non-responders - effects on prevalence estimates
}

\author{
Randi Selmer ${ }^{1}$, Anne Johanne Søgaard ${ }^{1}$, Espen Bjertness ${ }^{2}$ and Dag Thelle ${ }^{3}$ \\ ${ }^{1}$ Norwegian Institute of Public Health, Oslo, Norway \\ ${ }^{2}$ Department of General Practice and Community Medicine, Faculty of Medicine, University of Oslo, Norway \\ ${ }^{3}$ Akershus University Hospital, University of Oslo, Norway \\ Corresponding address: Randi Selmer, Norwegian Institute of Public Health, PO Box 4404 Nydalen, N-0403 Oslo, Norway \\ Phone: +4723408215 Fax: +4723408252 E-mail: randi.selmer@fhi.no
}

\begin{abstract}
Background: Low response rates in population studies may lead to serious selection bias. Most surveys try to increase attendance by sending one or more reminders, but we do not know whether these efforts actually lead to less bias. In the Oslo Health Study we have previously shown that sociodemographic background variables are distributed differently in attendees and non-attendees. The aim of this study is to investigate the effect of sending reminders to increase the rates of attendance in the Oslo Health Study, on the distribution of demographic variables and on the prevalence estimates of selected variables.

Methods: The analyses were based on linkage between data from public registers in Statistics Norway and data from the Oslo Health Study, a cross sectional population-based survey inviting all citizens in five agegroups 30-76 years old. Demographic variables from public health registers were compared in persons attending directly without reminders $(\mathrm{n}=12,495)$, in all participants attending after up to two reminders $(\mathrm{n}=18,769)$ and in the total invited population $(\mathrm{n}=40,874)$. Prevalence estimates were compared in the two groups of participants attending directly $(n=12,495)$ and after one or two reminders $(n=6,274)$ and in the combined group of all participants.

Results: By means of two reminders the attendance rate increased from $28 \%$ to $42 \%$ in men and from $33 \%$ to $49 \%$ in women. When comparing participants attending directly with the sample including all participants and the total invited population, the percentage in the 30 year olds increased from $20 \%$ to $22 \%$ and $28 \%$. The sample included successively more unmarried persons, $28 \%$ and $29 \%$ versus $35 \%$ in the total population, more persons born in non-western countries, $9 \%, 10 \%$ and $12 \%$, respectively, citizens living in the inner east district, $13 \%, 14 \%$ and $16 \%$, with lower secondary education, $14 \%, 15 \%$ and $17 \%$ and persons in the lowest income category, $9 \%, 10 \%$ and $12 \%$. When comparing the sample attending directly with the sample including all participants, the prevalence of diabetes in age group 75-76 years, increased from 8 to $9 \%$ in men and from 4 to $6 \%$ in women. Similarly, there was an increase in percent daily smokers, $14 \%$ vs. $16 \%$ in men and $16 \%$ vs. $17 \%$ in women, and symptoms of anxiety/depression (HSCL), $4 \%$ vs. $5 \%$ in men and $11 \%$ vs. $12 \%$ in women. The prevalence of good self-reported health decreased ( $70 \%$ vs. $67 \%$ in men, $60 \%$ vs. $57 \%$ in women) in $75-76$ year olds. There was no change in the other age groups. Persons born in non-western countries returned the first supplementary questionnaire $(57 \%$ of those attending) to a lesser extent than did persons born in Norway (87\%).

Conclusions: When including participants attending after reminders the sociodemographic distribution moved somewhat towards the distribution in the target population. The estimated prevalence figures showed small changes in the oldest age group and almost no change in the other groups. Increasing attendance through reminders had only minor effects on prevalence estimates and conclusions.
\end{abstract}

Key words: Reminder, epidemiological studies, health surveys, non-response, response bias, self-selection, bias, response rate

\section{INTRODUCTION}

The decrease in rates of attendance in health surveys during the last decades is a major concern. A low response rate may lead to serious selection bias. An indication of selection bias is that attendees often differ from the non-attendees in the distribution of demographic variables ${ }^{1-12}$. In the Oslo Health Study we have previously shown that sub-groups like young age-groups, unmarried, those not born in Norway, inner city dwellers, persons with unknown or lower secondary education, low income groups and receivers of disability benefit were underrepresented among the attendees ${ }^{13}$.

In the Oslo Health Study different efforts were made to increase the response rates ${ }^{14}$ and up to two 
reminding letters were sent. We do not know whether these efforts make the results more representative for the target population, whether the participants attending after reminders are similar to the participants attending directly (hesitant) or whether they are more like the non-attendees.

Several studies have demonstrated only moderate changes in prevalence estimates and sociodemographic distribution when comparing results of increasing the response rates in the range from around $30 \%$ to $70 \%{ }^{11,15-19}$. In our study the attendance rates increased from about $30 \%$ to $46 \%$ after two reminders. The advantage of our study is that we have almost complete information from public health registers for the whole invited population. The aim of the present analyses is to investigate the effect of sending reminders to increase the attendance rates in the Oslo Health Study on the distribution of demographic variables and on the prevalence estimates of selected variables. We also study if the group responding to a supplementary questionnaire is representative for the invited population.

\section{METHODS}

The Oslo Health Study (The acronym for the Norwegian title of the study is HUBRO, meaning "eagle owl"), a joint collaboration between the Oslo City Council, the University of Oslo and the National Health Screening Service, Oslo (now Norwegian Institute of Public Health), was conducted in Oslo from May 2000 to September 2001. The study has previously been described in more detail ${ }^{13,14}$. The aims of HUBRO were to identify health needs within the community and determine the priorities in the health sector, monitor the developments and trends of diseases and their associated risks, estimate the prevalence and later the incidence of chronic diseases, identify social and geographical differences in health and associated risk factors for disease, and to initiate research in order to further investigate the aetiology of major health problems.

An invitation letter, an information brochure and the main questionnaire were sent to Oslo citizens born in the following years: 1924, 1925, 1940, 1941, 1955, 1960 and 1970, two weeks prior to the appointment at the screening station. At the screening station a simple clinical examination was conducted and the main questionnaire was handed in. The participants were given two supplementary questionnaires, which they were instructed to fill in at home and return by mail in pre-addressed pre-stamped envelopes. Through linkage of the health survey data to public registries covering the total population, it has been possible to compare the rates of attendance in sociodemographic sub-groups ${ }^{13}$.

From the clinical examination and the main questionnaire we have used the following variables to study the effect of sending reminders on prevalence estimates:
- Diabetes: Have you or have you had diabetes?

- Body mass index: Body weight (kilogram)/(height $($ meter $))^{2}$

- Self-evaluated general health status: How would you describe your present state of health? (poor, not very good, good, very good)

- Self-reported daily smoking: Have you smoked or do you smoke daily? (yes - now, yes - earlier, never)

- Mental distress: Below is a list of various problems. Have you suffered from any of the following during the last week (including today)? (Put a cross for every problem). The 10 items asked are quoted in Strand et al., $2003^{20}$. These 10 items are an abridged version of the Hopkins Symptom CheckList $(\mathrm{HSCL})^{21}$. The average score in the HSCL-10 is calculated by dividing the total score on number of items answered (ranging between 1.00 'not at all' and 4.00 'extremely') ${ }^{20}$.

\section{ReSUlts}

\section{Reminders}

In men $28 \%$ attended directly without any reminder, increasing to $42 \%$ after two reminders (Table 1 ). The corresponding percentages for women were $33 \%$ and $49 \%$. Participants attending after one or two reminders differed significantly from participants attending directly in the distribution of age, marital status, country of birth, education and total income $(p<0.001)$ and region of residence $(\mathrm{p}=0.01)$. When comparing participants attending directly with the sample including all participants and the total invited population, the percentage in the 30 year olds increased from $20 \%$, to $22 \%$ and $28 \%$ (Table 1). The sample included successively more unmarried persons, $28 \%$ and $29 \%$ versus $35 \%$ in the total population, more persons born in nonwestern countries, $9 \%, 10 \%$ and $12 \%$, respectively, citizens living in the inner east district, $13 \%, 14 \%$ and $16 \%$, with lower secondary education, $14 \%, 15 \%$ and $17 \%$ and persons in the lowest income category, $9 \%$, $10 \%$ and $12 \%$.

\section{Supplementary questionnaire}

Of those who attended at the screening station, $84 \%$ returned the first supplementary questionnaire $(37 \%$ of the invited population). Persons born in non-western countries returned this questionnaire $(57 \%)$ to a lesser extent than did persons born in Norway (87\%). Thus, of all the invited, the response rate to the questionnaire was only $22 \%$ in persons born in non-western countries compared with $40 \%$ in those born in Norway. Similarly, persons with low education returned the supplementary questionnaire to a lesser extent than persons with high education. The distribution of the other sociodemographic variables in responders to the supplementary questionnaire was similar to the distribution in the group including all attendees. 
Table 1. Sociodemographic variables in participants attending directly, all participants and all invited persons to the Oslo Health Study 2000-2001.

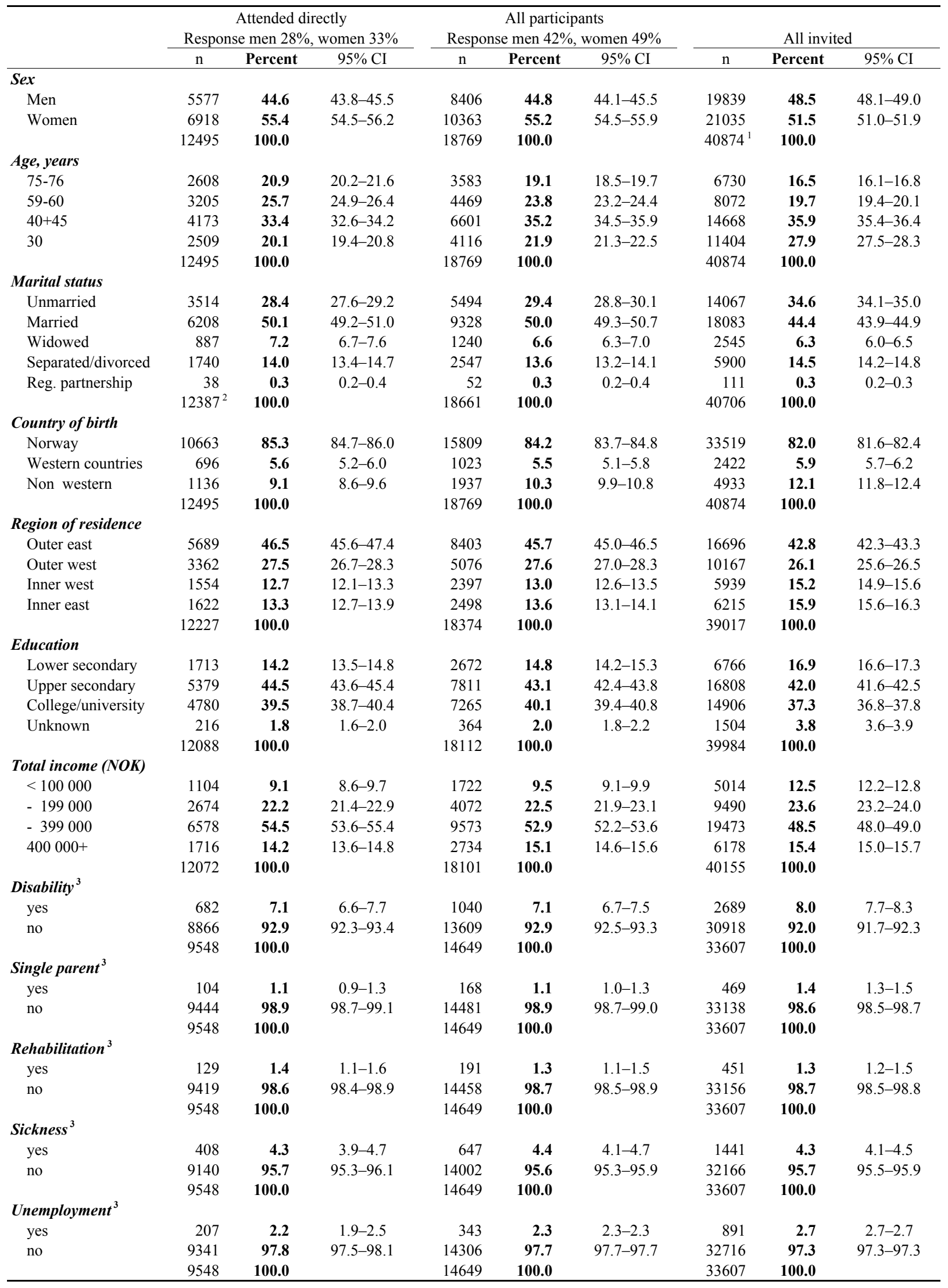

${ }^{1}$ Numbers differ slightly from the official numbers due to updating of data register with respect to number of deaths before screening

${ }^{2}$ The sub totals are not the same due to incomplete registration in the official registers

${ }^{3}$ Social security benefits for age groups $<70$ years 


\section{Prevalence estimates}

In the oldest age group of men, participants attending after one or two reminders reported significantly more diabetes, daily smoking, symptoms of anxiety/depression (HSCL $\geq 1.85$ ) and less often good or excellent health compared to those attending directly (Table 2). The same was seen in elderly women except for the percentage reporting symptoms of anxiety/depression which did not differ significantly. The prevalence estimates for the sample attending directly, however, differed only moderately from the estimates based on the sample including all participants. In the younger age groups the prevalence estimates were almost the same if we included participants attending after reminders or not (Table 2 ).

\section{DISCUSSION}

We attempted to increase the response rate in HUBRO, by carrying out resource-demanding "reminder-rounds". By sending two reminders the response rates showed a relatively greater increase among young persons compared with older cohorts, among unmarried individuals, persons born in nonwestern countries, inner-city dwellers and among persons with lower secondary education and in the lowest income category, compared with other groups. The distribution of sociodemographic variables, however, changed very little when we included persons participating after reminders. The distribution moved somewhat against the distribution for the total invited population, but still it was closer to the distribution for the initial participants than to the distribution for the total invited population. Thus, increasing the attendance rate from $30 \%$ to $46 \%$ through two reminders had little impact on the sociodemographic distribution. We reached, however, to a certain extent relatively more persons with diabetes, poor self-reported health and symptoms of anxiety/depression and more daily smokers in the oldest age groups. In the younger age groups the prevalence estimates showed almost no change. Overall the prevalence estimates changed very little after the reminder rounds. But of course, increasing the sample size has impact on the precision of the estimates, making it possible to do different subgroup analyses.

The general validity of this finding is supported by several other studies. Increasing the attendance rate from $60 \%$ to $70 \%$ did not have a large impact on the prevalence figures in a previous Norwegian study ${ }^{15}$. Comparing two parts of the same Dutch survey (attendance $45 \%$ and $24 \%$ of the total sample), gave small differences in the distribution of sociodemographic variables and prevalence figures ${ }^{11}$. Comparing response rates of $40 \%$ and $49 \%$ in a randomised trial comparing the effect of length of questionnaire on response, gave no difference in the proportion who claimed to have good health/excellent health ${ }^{16}$. A multicentre osteoporosis study comparing samples with response rate categories of $<50 \%, 50-60 \%$ and $>60 \%$ suggests no major influence of response on the observed differences in risk factors of osteoporosis between responders and non-responders ${ }^{17}$. Finally, two non-response analyses of public opinion polls comparing response rates of about $60-70 \%$ with corresponding polls of $30-40 \%$ (less attempts to reach the respondents) produced almost similar results ${ }^{18,19}$.

It is not obvious that an even higher response rate in HUBRO would have prevented selection bias. In the Dutch Amenities and Services Utilisation Survey, a study attempting to reach just about everybody, late responders differed from "pursuable non-responders" - and both groups differed from real refusers ${ }^{22}$. Results from the Leiden study of older persons showed that increasing the response rate from $74 \%$ to $87 \%$ did actually introduce a bias in the prevalence estimates ${ }^{23}$. These additional responders had poorer health, whereas the remaining non-responders had equal or better health than the originally $74 \%$ responders, but had somewhat poorer mood. That those who actively refused to participate are similar to respondents in most respects, are supported by findings from the previously mentioned Dutch survey ${ }^{22}$. Those refusing were only slightly less lower class and slightly more inner city dwellers than the responders.

From the present analyses we conclude that increasing attendance through reminders had only minor effects on prevalence estimates and conclusions.

\section{REFERENCES}

1. Belsby L, Vedø A. Non-response analysis of the Norwegian Health Survey 1995 [Frafallsanalyse av Helseundersøkelsen 1995] (in Norwegian). 3/98. 1998. Oslo, Statistics Norway. Notater.

2. Berglund G, Nilsson P, Eriksson KF, Nilsson JA, Hedblad B, Kristenson H, Lindgarde F. Long-term outcome of the Malmö preventive project: mortality and cardiovascular morbidity. J Intern Med 2000; 247: 19-29.

3. Boström G, Hallqvist J, Haglund BJ, Romelsjö A, Svanström L, Diderichsen F. Socioeconomic differences in smoking in an urban Swedish population. The bias introduced by non-participation in a mailed questionnaire. Scand J Soc Med 1993; 21: 77-82.

4. Hoeymans N, Feskens EJ, Van Den Bos GA, Kromhout D. Non-response bias in a study of cardiovascular diseases, functional status and self-rated health among elderly men. Age Ageing 1998; 27: 35-40. 
Table 2. Prevalence estimates (\%) in participants who attended directly, with one or two reminders and in all attendees. Pvalue for equality between groups of attendees. The Oslo Health Study 2000-2001.

\begin{tabular}{|c|c|c|c|c|c|c|c|c|c|c|}
\hline & \multicolumn{3}{|c|}{ Attended directly } & \multicolumn{3}{|c|}{ Attended with one or two reminders } & \multirow[b]{2}{*}{$\mathrm{p}$-value } & \multicolumn{3}{|c|}{ All attendees } \\
\hline & $\mathrm{n}$ & $\%$ & $95 \% \mathrm{CI}$ & $\mathrm{n}$ & $\%$ & $95 \% \mathrm{CI}$ & & $\mathrm{n}$ & $\%$ & $95 \% \mathrm{CI}$ \\
\hline \multicolumn{11}{|c|}{ Men (age) } \\
\hline \multicolumn{11}{|l|}{ Diabetes } \\
\hline $75-76$ & 87 & 7.7 & $6.2-9.3$ & 45 & 12.3 & $8.9-15.7$ & 0.01 & 132 & 8.9 & $7.4-10.3$ \\
\hline $59-60$ & 78 & 5.4 & $4.2-6.6$ & 41 & 6.7 & $4.7-8.7$ & 0.25 & 119 & 5.8 & $4.8-6.8$ \\
\hline $40-45$ & 29 & 1.6 & $1.0-2.2$ & 23 & 2.2 & $1.3-3.0$ & 0.29 & 52 & 1.8 & $1.3-2.3$ \\
\hline 30 & 3 & 0.3 & $0.0-0.6$ & 5 & 0.7 & $0.1-1.4$ & 0.17 & 8 & 0.4 & $0.1-0.8$ \\
\hline \multicolumn{11}{|c|}{ Daily smoking } \\
\hline $75-76$ & 154 & 13.6 & $11.6-15.6$ & 86 & 22.9 & $18.7-27.2$ & 0.00 & 240 & 15.9 & $14.1-17.7$ \\
\hline $59-60$ & 365 & 24.8 & $22.6-27.0$ & 177 & 28.4 & $24.8-31.9$ & 0.09 & 542 & 25.9 & $24.0-27.8$ \\
\hline $40-45$ & 574 & 31.6 & $29.4-33.7$ & 354 & 32.6 & $29.8-35.4$ & 0.56 & 928 & 32.0 & $30.3-33.7$ \\
\hline 30 & 266 & 24.1 & $21.5-26.6$ & 149 & 21.1 & $18.1-24.1$ & 0.14 & 415 & 22.9 & $21.0-24.8$ \\
\hline \multicolumn{11}{|l|}{$\mathrm{BMI} \geq 30$} \\
\hline $75-76$ & 118 & 11.4 & $9.5-13.4$ & 42 & 13.1 & $9.4-16.8$ & 0.42 & 160 & 11.8 & $10.1-13.5$ \\
\hline $59-60$ & 267 & 18.4 & $16.4-20.4$ & 112 & 19.1 & $15.9-22.3$ & 0.71 & 379 & 18.6 & $16.9-20.3$ \\
\hline $40-45$ & 250 & 13.7 & $12.1-15.3$ & 158 & 15.4 & $13.2-17.6$ & 0.22 & 408 & 14.3 & $13.0-15.6$ \\
\hline 30 & 122 & 11.0 & $9.1-12.8$ & 78 & 11.3 & $8.9-13.7$ & 0.83 & 200 & 11.1 & $9.7-12.6$ \\
\hline \multicolumn{11}{|c|}{$\mathrm{HSCL} \geq 1.85$} \\
\hline $75-76$ & 39 & 3.5 & $2.4-4.6$ & 28 & 7.9 & $5.1-10.7$ & 0.00 & 67 & 4.6 & $3.5-5.7$ \\
\hline $59-60$ & 100 & 7.3 & $5.9-8.6$ & 49 & 8.5 & $6.2-10.8$ & 0.36 & 149 & 7.6 & $6.5-8.8$ \\
\hline $40-45$ & 190 & 11.1 & $9.6-12.5$ & 93 & 9.1 & $7.4-10.9$ & 0.11 & 283 & 10.3 & $9.2-11.5$ \\
\hline 30 & 63 & 5.9 & $4.5-7.3$ & 41 & 6.0 & $4.2-7.8$ & 0.91 & 104 & 5.9 & $4.8-7.0$ \\
\hline \multicolumn{11}{|c|}{ Good/excellent health } \\
\hline $75-76$ & 772 & 69.7 & $67.0-72.4$ & 202 & 59.1 & $53.9-64.3$ & 0.00 & 974 & 67.2 & $64.8-69.6$ \\
\hline $59-60$ & 1077 & 73.7 & $71.5-76.0$ & 428 & 69.7 & $66.1-73.3$ & 0.06 & 1505 & 72.5 & $70.6-74.5$ \\
\hline $40-45$ & 1462 & 80.3 & $78.5-82.2$ & 858 & 79.5 & $77.1-81.9$ & 0.60 & 2320 & 80.0 & $78.6-81.5$ \\
\hline 30 & 989 & 89.3 & $87.5-91.2$ & 649 & 91.9 & $89.9-93.9$ & 0.07 & 1638 & 90.3 & $89.0-91.7$ \\
\hline \multicolumn{11}{|c|}{ Women (age) } \\
\hline \multicolumn{11}{|l|}{ Diabetes } \\
\hline $75-76$ & 64 & 4.5 & $3.4-5.5$ & 48 & 8.5 & $6.2-10.8$ & 0.00 & 112 & 5.6 & $4.6-6.6$ \\
\hline $59-60$ & 45 & 2.7 & $1.9-3.5$ & 20 & 3.3 & $1.9-4.8$ & 0.42 & 65 & 2.9 & $2.2-3.6$ \\
\hline $40-45$ & 42 & 1.8 & $1.3-2.4$ & 30 & 2.3 & $1.5-3.2$ & 0.32 & 72 & 2.0 & $1.6-2.5$ \\
\hline 30 & 7 & 0.5 & $0.1-0.9$ & 6 & 0.7 & $0.1-1.3$ & 0.58 & 13 & 0.6 & $0.3-0.9$ \\
\hline \multicolumn{11}{|c|}{ Daily smoking } \\
\hline $75-76$ & 227 & 15.5 & $13.7-17.4$ & 115 & 19.9 & $16.6-23.2$ & 0.02 & 342 & 16.8 & $15.2-18.4$ \\
\hline $59-60$ & 413 & 24.3 & $22.2-26.3$ & 164 & 26.9 & $23.4-30.5$ & 0.19 & 577 & 25.0 & $23.2-26.7$ \\
\hline $40-45$ & 754 & 32.7 & $30.8-34.7$ & 434 & 33.2 & $30.7-35.8$ & 0.78 & 1188 & 32.9 & $31.4-34.4$ \\
\hline 30 & 317 & 23.1 & $20.8-25.3$ & 190 & 21.7 & $19.0-24.4$ & 0.46 & 507 & 22.5 & $20.8-24.3$ \\
\hline \multicolumn{11}{|c|}{$\mathrm{BMI} \geq 30$} \\
\hline $75-76$ & 235 & 16.1 & $14.2-18.0$ & 95 & 19.0 & $15.6-22.4$ & 0.14 & 330 & 16.9 & $15.2-18.5$ \\
\hline $59-60$ & 291 & 17.0 & $15.2-18.8$ & 120 & 20.7 & $17.4-23.9$ & 0.05 & 411 & 17.9 & $16.3-19.5$ \\
\hline $40-45$ & 281 & 12.1 & $10.8-13.5$ & 199 & 16.0 & $14.0-18.1$ & 0.00 & 480 & 13.5 & $12.4-14.6$ \\
\hline 30 & 119 & 8.6 & $7.1-10.1$ & 81 & 9.9 & $7.9-12.0$ & 0.29 & 200 & 9.1 & $7.9-10.3$ \\
\hline \multicolumn{11}{|c|}{$\mathrm{HSCL} \geq 1.85$} \\
\hline $75-76$ & 154 & 11.5 & $9.8-13.2$ & 75 & 14.6 & $11.5-17.6$ & 0.07 & 229 & 12.3 & $10.8-13.8$ \\
\hline $59-60$ & 246 & 15.7 & $13.9-17.5$ & 84 & 15.2 & $12.2-18.2$ & 0.81 & 330 & 15.5 & $14.0-17.1$ \\
\hline $40-45$ & 295 & 13.4 & $11.9-14.8$ & 167 & 13.4 & $11.5-15.3$ & 0.96 & 462 & 13.4 & $12.3-14.5$ \\
\hline 30 & 126 & 9.5 & $7.9-11.0$ & 103 & 12.3 & $10.1-14.5$ & 0.04 & 229 & 10.6 & $9.3-11.9$ \\
\hline \multicolumn{11}{|c|}{ Good/excellent health } \\
\hline $75-76$ & 861 & 59.9 & $57.3-62.4$ & 266 & 48.9 & $44.7-53.1$ & 0.00 & 1127 & 56.9 & $54.7-59.0$ \\
\hline $59-60$ & 1131 & 66.0 & $63.7-68.2$ & 356 & 60.0 & $56.1-64.0$ & 0.09 & 1487 & 64.5 & $62.5-66.4$ \\
\hline $40-45$ & 1797 & 77.8 & $76.1-79.5$ & 1011 & 77.9 & $75.7-80.2$ & 0.91 & 2808 & 77.8 & $76.5-79.2$ \\
\hline 30 & 1207 & 87.3 & $85.6-89.1$ & 728 & 83.2 & $80.7-85.7$ & 0.01 & 1935 & 85.7 & $84.3-87.2$ \\
\hline
\end{tabular}


5. Jackson R, Chambless LE, Yang K, Byrne T, Watson R, Folsom A, Shahar E, Kalsbeek W. Differences between respondents and nonrespondents in a multicenter community-based study vary by gender and ethnicity. The Atherosclerosis Risk in Communities (ARIC) Study Investigators. J Clin Epidemiol 1996; 49: 1441-6.

6. Jacobsen BK, Thelle DS. The Tromsø Heart Study: responders and non-responders to a health questionnaire, do they differ? Scand J Soc Med 1988; 16: 101-4.

7. Korkeila K, Suominen S, Ahvenainen J, Ojanlatva A, Rautava P, Helenius H, Koskenvuo M. Non-response and related factors in a nation-wide health survey. Eur J Epidemiol 2001; 17: 991-9.

8. Launer LJ, Wind AW, Deeg DJ. Nonresponse pattern and bias in a community-based cross-sectional study of cognitive functioning among the elderly. Am J Epidemiol 1994; 139: 803-12.

9. Osler M, Schroll M. Differences between participants and non-participants in a population study on nutrition and health in the elderly. Eur J Clin Nutr 1992; 46: 289-95.

10. Reijneveld SA, Stronks K. The impact of response bias on estimates of health care utilization in a metropolitan area: the use of administrative data. Int J Epidemiol 1999; 28: 1134-40.

11. Van Loon AJ, Tijhuis M, Picavet HS, Surtees PG, Ormel J. Survey non-response in the Netherlands. Effects on prevalence estimates and associations. Ann Epidemiol 2003; 13: 105-10.

12. Wilhelmsen L, Tibblin G, Werkö L. A primary preventive study of Gothenburg, Sweden. Prev Med 1972; 1: 153-60.

13. Søgaard AJ, Selmer R, Bjertness E, Thelle D. The Oslo Health Study: The impact of self-selection in a large, population-based survey (Submitted).

14. Søgaard AJ, Selmer R. Norwegian Institute of Public Health. The Oslo Health Study. http://www.fhi.no/tema/ helseundersokelse/oslo/index.html (Electronic Citation).

15. Lund E, Gram IT. Response rate according to title and length of questionnaire. Scand J Soc Med 1998; 26: 154-60.

16. Iglesias C, Torgerson D. Does length of questionnaire matter? A randomised trial of response rates to a mailed questionnaire. J Health Serv Res Policy 2000; 5: 219-21.

17. O'Neill TW, Marsden D, Silman AJ. Differences in the characteristics of responders and non-responders in a prevalence survey of vertebral osteoporosis. European Vertebral Osteoporosis Study Group. Osteoporos Int 1995; 5: 327-34.

18. Keeter S, Miller C, Kohut A, Groves RM, Presser S. Consequences of reducing nonresponse in a national telephone survey. Public Opin Q 2000; 64: 125-48.

19. Curtin R, Presser S, Singer E. The effects of response rate changes on the index of consumer sentiment. Public Opin Q 2000; 64: 413-28.

20. Strand BH, Dalgard OS, Tambs K, Rognerud M. Measuring the mental health status of the Norwegian population: a comparison of the instruments SCL-25 SCL-10, SCL-5 and MHI-5 (SF-36). Nord J Psychiatry 2003; 57: 113-8.

21. Derogatis LR, Lipman RS, Rickels K, Uhlenhuth EH, Covi L. The Hopkins Symptom Checklist (HSCL): a self-report symptom inventory. Behav Sci 1974; 19: 1-15.

22. Stoop I, Louwen F. Late response and very late response. A study of non-response using frame and wave data. Oslo, Norway. 12. International Workshop on Household Survey Nonresponse. 12-9-2001.

23. der Wiel AB, van Exel E, de Craen AJ, Gussekloo J, Lagaay AM, Knook DL, Westendorp RG. A high response is not essential to prevent selection bias: results from the Leiden 85-plus study. J Clin Epidemiol 2002; 55: 1119-25. 